\title{
Características químicas e valores energéticos de farelos de soja do oeste e sudoeste do Paraná
}

\author{
Chemistry characteristics and energetics values of soybean meals \\ Clovis Rieger ${ }^{\mathrm{I}}$ Vladimir de Oliveira ${ }^{\mathrm{II}}$ Paulo Alberto Lovatto $^{\mathrm{III}}$ \\ Jocélio dos Santos Araújo ${ }^{\mathrm{II}}$ Érika Cosendey Toledo Mello Peixoto ${ }^{\mathrm{II}}$ \\ Marcelo Aparecido da Silva ${ }^{\mathrm{IV}}$
}

\begin{abstract}
-NOTA-
RESUMO

Foi realizado um estudo para determinar a variabilidade de características químicas e valores energéticos de farelos de soja (FS) do oeste e sudoeste do Paraná. Foram estudadas 40 amostras colhidas em 10 processadores e distribuidores durante quatro meses consecutivos. Houve diferenças $(P<0,05)$ entre os teores de matéria seca (MS) dos

the soybean meals 5 and 7 had higher levels of Ca (0.36 and 0.36 , respectively). The calculated TMEn value of soybean meal 8 was higher $(P<0.05)$ than soybean meals 5 and 10 (2.65 versus 2.51 and 2.50Mcal kg-1, respectively). The chemical composition of soybean meal from the West and Southwest Paraná state is homogenous and near that found in scientific literature, except for neutral detergent fiber, acid detergent fiber, iron and manganese.
\end{abstract} farelos de soja (FS) analisados. O FS 10 apresentou menor $(P<0,05)$ teor de MS (86,72\%) em relação aos FS 2, 4, 5, 6 e 9 (88,96, 90,60,89,19, 89,08 e 88,72\%, respectivamente). $O$ FS 4 teve menor conteúdo de Ca (0,31\%), enquanto os FS 5 e 7 mostraram os maiores teores de Ca $(0,36$ e $0,36 \%$, respectivamente). Ocorreram diferenças $(P<0,05)$ entre os valores de energia metabolizável verdadeira (EMVn) calculados, com o FS 8 apresentando a maior concentração (2,65 Mcal $\left.\mathrm{kg}^{-1}\right)$ e os FS 5 e 10 os menores teores de energia calculados (2,51 e 2,50Mcal kg-1, respectivamente). Pode-se concluir que a composição química dos farelos de soja das regiões oeste e sudoeste do Paraná apresenta pouca variação $e$, exceto para a fibra em detergente neutro, fibra em detergente ácido, ferro e manganês, os valores encontrados são próximos daqueles citados na literatura.

Palavras-chave: alimentação animal, aves, suínos.

\section{ABSTRACT}

A study was conducted to determine the variability on chemical and nutritional characteristics of soybean meal from the West and Southwest Paraná state. Forty samples of soybean meal were collected in ten different processors and distributors during four months consecutively. There were differences $(P<0.05)$ among the dry matter $(D M)$ in samples of soybean meal analyzed. The soybean meal 10 had less $(P<0.05)$ level of DM (86.72\%) compared with soybean meals 2, 4, 5, 6 and 9 (88.96, 90.60, 89.19, 89.08 and 88.72\%, respectively). The soybean meal 4 showed less content of Ca $(0.31 \%)$, while
Key words: broilers, feedstuffs, swine.

O farelo de soja (FS) é um subproduto derivado do processamento do grão de soja integral para extração do óleo e é amplamente utilizado em dietas de aves e suínos. Estudos comparando FS produzidos em diferentes países indicaram que sua composição química e valor energético são variáveis (VAN KEMPEN et al., 2002; KARR-LILIENTHAL et al., 2005).

O Paraná é um dos principais responsáveis pela produção nacional de soja e um importante fornecedor de farelo para a alimentação animal, destacando-se as regiões oeste e sudoeste do Estado. Contudo, não há na literatura estudos relatando a variabilidade na composição dos farelos de soja dessas regiões. Assim, o presente estudo foi realizado com o objetivo de determinar a variabilidade de características químicas e valor energético de diferentes FS das regiões oeste e sudoeste do Paraná.

O estudo foi conduzido na Universidade Estadual do Oeste do Paraná (UNIOESTE), campus de

\footnotetext{
IDepartamento Técnico Comercial. M.Cassab Indústria e Comércio Ltda.

IIUniversidade Estadual do Oeste do Paraná (UNIOESTE). Rua Pernambuco, 1777, CP 1008, 85960-000, Mal. Cândido Rondon, PR, Brasil. Email: v_olliveira@yahoo.com.br.*Autor para correspondência.

IIIDepartamento de Zootecnia, Universidade Federal de Santa Maria (UFSM), Santa Maria, RS, Brasil.

Iv Departamento Técnico Agroceres Nutrição Animal, Rio Claro, SP, Brasil.
} 
Marechal Cândido Rondon, PR, durante o ano de 2005. Foram colhidas 40 amostras de FS, com casca, por um período de quatro meses consecutivos (fevereiro, março, abril e maio) em dez processadores e distribuidores das regiões oeste e sudoeste do Paraná. A colheita das amostras foi realizada aleatoriamente em, no mínimo, $10 \%$ dos sacos de um lote para colheita. Em condições de estocagem a granel, a colheita foi realizada em vários pontos no sentido de obter uma amostragem homogênea. Todas as amostras foram obtidas com auxílio de caladores para amostragem de farelos em sacos ou a granel. O procedimento utilizado na amostragem seguiu a recomendação de BUTOLLO (2002).

A umidade foi obtida após a permanência da amostra em estufa à temperatura de $105^{\circ} \mathrm{C}$ por um período de 24 horas. $\mathrm{O}$ nitrogênio foi determinado pela metodologia de Kjeldahl. O extrato etéreo foi obtido pela lavagem com éter de petróleo em aparelho extrator tipo Soxhlet. A matéria mineral (MM) foi obtida pela queima da matéria orgânica em forno mufla mantido na temperatura aproximada de $550^{\circ} \mathrm{C}$. As fibras em detergente neutro e detergente ácido foram obtidas pela digestão e filtragem. O cálcio foi determinado indiretamente por meio de titulação com permanganato de potássio. O fósforo total foi quantificado por colorimetria. A concentração de magnésio, manganês, cobre, ferro, zinco e potássio foi obtida após a digestão ácida, sendo a leitura efetuada em espectrofotômetro de absorção atômica. A atividade ureática e a solubilidade da proteína em hidróxido de potássio a 0,2\% foram determinadas conforme metodologia descrita em COMPÊNDIO (1998). A energia metabolizável verdadeira (EMVn) foi calculada com a equação proposta por JANSSEN (1989).

Os dados foram submetidos à análise de variância utilizando o delineamento em blocos casualizados, sendo que o mês de coleta foi o critério adotado para formar os blocos. As diferenças entre as médias foram comparadas utilizando o teste de Tukey a $5 \%$ de probabilidade.

Os resultados das variáveis analisadas nas amostras de FS são apresentados na tabela 1. Houve diferença $(\mathrm{P}<0,05)$ entre os teores de MS dos FS analisados. O FS 10 apresentou umidade superior $(\mathrm{P}<0,05)$ aos FS 2, 4, 5, 6 e 9. A concentração de MS dos FS 1, 3, 7 e 8 foi intermediária e semelhante $(P>0,05)$ aos demais. Em um estudo com 55 amostras de FS oriundas de sete regiões diferentes dos Estados Unidos, também houve variações no teor de MS (GRIESHOP et al., 2003). O teor médio de MS dos FS analisados no presente estudo foi de $88,58 \%$ e também se observou pequena variação no teor de MS dos FS, exceto no caso do FS 10.
Não foram encontradas diferenças $(\mathrm{P}>0,05)$ entre os teores de PB dos FS analisados. Estes resultados são semelhantes aos descritos por CROMWELL et al. (1999), que analisaram FS de nove diferentes origens. Por outro lado, GRIESHOP et al. (2003) observaram variações na quantidade média de proteína de $\mathrm{PB}$ de FS produzidos em 55 unidades processadores dos Estados Unidos. Pequenas diferenças no teor de $\mathrm{PB}$ podem ocorrer devido aos procedimentos laboratoriais adotados para análise do nitrogênio (CROMWELL et al., 1999). O conteúdo médio de PB obtido no presente estudo foi de 45,39\%. A tabela de composição de alimentos publicada por ROSTAGNO et al. (2005) contêm valores de PB para dois tipos de FS (45 e 48\%) classificados de acordo com o teor médio de proteína bruta. Com base nos resultados médios obtidos neste estudo, pode-se afirmar que as informações de ROSTAGNO et al. (2005) possivelmente refletem os FS (com casca) disponíveis para comercialização.

$\mathrm{O}$ EE foi semelhante $(\mathrm{P}>0,05)$ nos diferentes FS estudados. O conteúdo médio de EE foi de 1,76\%, com uma amplitude alta (0,93 - 2,57\% da MS). Esses resultados são semelhantes aos obtidos por KARRLILIENTHAL et al. (2005). A variação encontrada nos valores de EE pode ser explicada pelas diferenças no processamento utilizado para a extração do óleo. O valor médio de EE calculado com base em todas as amostras (1,76\%) foi muito próximo aos citados por ROSTAGNO et al. (2005) (1,87\%).

Não foram detectadas diferenças $(\mathrm{P}>0,05)$ entre os valores de FDN encontrados nos FS analisados. $\mathrm{O}$ valor médio obtido no presente estudo foi de $11,46 \%$, muito próximo ao valor médio de 11,49\%, citado por OST et al. (2005), mas inferior ao teor de $13,86 \%$ mencionado por ROSTAGNO et al. (2005). O conteúdo de FDN é uma estimativa da quantidade de carboidratos de baixa digestibilidade para monogástricos (cascas e polissacarídeos nãoamiláceos). Quanto maior a inclusão de casca no farelo, menor é a quantidade de proteína (BUTOLLO, 2002). Isto ficou evidenciado neste estudo, pois se detectou correlação negativa $(\mathrm{r}=-0,43 ; \mathrm{P}<0,01)$ entre concentração de FDN e PB.

Não ocorreram diferenças $(P>0,05)$ na concentração de FDA dos FS analisados. O valor médio de FDA obtido no presente estudo (6,32\%) é inferior aos de ROSTAGNO et al. (2005) e RODRIGUES et al. (2002), que encontraram valores de 7,79 e 7,89\%, respectivamente.

O conteúdo de MM foi semelhante $(\mathrm{P}>0,05)$ entre todos os FS analisados, sendo a concentração média de 5,48\%. São valores muito próximos daqueles 
Tabela 1 - Composição química, valores energéticos, atividade ureática (IAU) e proteína solúvel (PS) em hidróxido de potássio a 0,2\% de diferentes amostras de farelos de soja (FS).

\begin{tabular}{|c|c|c|c|c|c|c|c|c|c|c|c|c|}
\hline Variável & FS1 & FS2 & FS3 & FS4 & FS5 & FS6 & FS7 & FS8 & FS9 & FS10 & Média & Prob. \\
\hline MS, $\%$ & $88,51^{\mathrm{ab}}$ & $88,96^{\mathrm{b}}$ & $88,17^{\mathrm{ab}}$ & $89,60^{\mathrm{b}}$ & $89,19^{b}$ & $89,08^{b}$ & $88,28^{\mathrm{ab}}$ & $88,59^{\mathrm{ab}}$ & $88,72^{b}$ & $86,72^{\mathrm{a}}$ & 88,58 & $<0,05$ \\
\hline $\mathrm{PB}^{1}, \%$ & 45,03 & 45,08 & 45,80 & 45,49 & 44,55 & 45,56 & 45,55 & 45,54 & 45,78 & 45,51 & 45,59 & NS \\
\hline $\mathrm{EE}^{1}, \%$ & 1,77 & 2,12 & 1,72 & 1,46 & 0,93 & 1,80 & 2,12 & 1,99 & 2,10 & 2,57 & 1,76 & NS \\
\hline $\mathrm{FDN}^{1}, \%$ & 11,71 & 12,35 & 11,75 & 11,40 & 12,13 & 10,76 & 11,00 & 11,40 & 11,15 & 11,00 & 11,46 & NS \\
\hline $\mathrm{FDA}^{1}, \%$ & 5,74 & 6,78 & 5,84 & 6,25 & 6,53 & 6,58 & 5,77 & 6,34 & 6,51 & 6,75 & 6,32 & NS \\
\hline $\mathrm{MM}^{1}, \%$ & 5,39 & 5,20 & 5,45 & 5,27 & 5,53 & 5,61 & 5,67 & 5,70 & 5,54 & 5,50 & 5,48 & NS \\
\hline $\mathrm{Ca}^{1}, \%$ & $0,36^{\mathrm{ab}}$ & $0,32^{\mathrm{ab}}$ & $0,33^{\mathrm{ab}}$ & $0,31^{\mathrm{b}}$ & $0,36^{\mathrm{a}}$ & $0,34^{\mathrm{ab}}$ & $0,36^{\mathrm{a}}$ & $0,34^{\mathrm{ab}}$ & $0,35^{\mathrm{ab}}$ & $0,34^{\mathrm{ab}}$ & 0,34 & $<0,05$ \\
\hline $\mathrm{P}^{1}, \%$ & 0,63 & 0,63 & 0,63 & 0,63 & 0,63 & 0,63 & 0,63 & 0,63 & 0,63 & 0,63 & 0,64 & NS \\
\hline $\mathrm{K}^{1}, \%$ & 1,89 & 1,91 & 1,98 & 2,04 & 2,07 & 1,92 & 1,94 & 1,99 & 1,95 & 1,94 & 1,96 & NS \\
\hline $\mathrm{Mg}^{1}, \%$ & 0,43 & 0,41 & 0,42 & 0,40 & 0,40 & 0,40 & 0,40 & 0,40 & 0,39 & 0,40 & 0,41 & NS \\
\hline $\mathrm{Fe}^{1,} \mathrm{mg} \mathrm{kg}^{-1}$ & $304^{\mathrm{ab}}$ & $294^{\mathrm{abc}}$ & $263^{\text {bcde }}$ & $233^{e}$ & $245^{\text {de }}$ & $272^{\text {bcde }}$ & $262^{\text {bcde }}$ & $256^{\text {cde }}$ & $278^{\text {bcd }}$ & $324^{\mathrm{a}}$ & 273 & $<0,01$ \\
\hline $\mathrm{Mn}^{1}, \mathrm{mg} \mathrm{kg}^{-1}$ & $40^{\mathrm{ab}}$ & $39^{\mathrm{ab}}$ & $37^{\mathrm{b}}$ & $37^{\mathrm{b}}$ & $39^{\mathrm{ab}}$ & $38^{\mathrm{b}}$ & $38^{\mathrm{b}}$ & $44^{\mathrm{a}}$ & $45^{\mathrm{a}}$ & $37^{\mathrm{b}}$ & 39 & $<0,01$ \\
\hline $\mathrm{Cu}^{1}, \mathrm{mg} \mathrm{kg}^{-1}$ & 18 & 17 & 17 & 16 & 16 & 16 & 16 & 16 & 16 & 15 & 16 & NS \\
\hline $\mathrm{Zn}^{1}, \mathrm{mg} \mathrm{kg}^{-1}$ & 64 & 64 & 59 & 61 & 62 & 63 & 61 & 65 & 65 & 63 & 63 & NS \\
\hline $\mathrm{EMVn}^{1}$, Mcal kg${ }^{-1}$ & $2,56^{\mathrm{ab}}$ & $2,60^{\mathrm{ab}}$ & $2,56^{\mathrm{ab}}$ & $2,58^{\mathrm{ab}}$ & $2,51^{b}$ & $2,59^{\mathrm{ab}}$ & $2,59^{\mathrm{ab}}$ & $2,65^{\mathrm{a}}$ & $2,60^{\mathrm{ab}}$ & $2,50^{\mathrm{b}}$ & 2,57 & $<0,05$ \\
\hline IAU, $\Delta \mathrm{pH}^{-1}$ & 0,05 & 0,06 & 0,06 & 0,06 & 0,06 & 0,09 & 0,07 & 0,06 & 0,06 & 0,08 & 0,06 & NS \\
\hline PS em $\mathrm{KOH}$ & $89,8^{\mathrm{a}}$ & $87,2^{\mathrm{ab}}$ & $85,3^{\mathrm{ab}}$ & $77,2^{\mathrm{b}}$ & $84,7^{\mathrm{ab}}$ & $84,9^{\mathrm{ab}}$ & $85,0^{\mathrm{ab}}$ & $81,0^{\mathrm{ab}}$ & $84,0^{\mathrm{ab}}$ & $83,4^{\mathrm{ab}}$ & 84,2 & $<0,01$ \\
\hline
\end{tabular}

${ }^{1}$ Valores expressos com base em 88,5\% de matéria seca. ${ }^{2}$ Valor de probabilidade para efeito do farelo de soja na variável analisada. * Médias seguidas de letras diferentes diferem pelo teste de Tukey a 5\%. MS=Matéria seca; PB=Proteína bruta; EE=Extrato etéreo; FDN=Fibra detergente neutro; FDA=Fibra detergente ácido; MM=Matéria mineral; EMVn=Energia metabolizável verdadeira; IAU=Índice de atividade ureática; PS=Proteína solúvel em hidróxido de potássio a 0,2\%.

publicados em vários outros estudos nacionais, como 5,71\%(RODRIGUES et al., 2002) e 5,90\% (ROSTAGNO et al., 2005). O conteúdo de minerais no solo e sua disponibilidade para o tecido vegetal influenciam a quantidade de minerais do FS (KARR-LILIENTHAL et al., 2004).

A concentração de Ca dos FS analisados diferiu significativamente $(\mathrm{P}<0,05)$. Além das características de solo, diferenças entre os procedimentos laboratoriais influenciam a concentração de Ca do FS (CROMWELL et al., 1999). O valor médio de Ca, calculado entre todas as amostras, foi de $0,34 \%$, que é superior ao valor de $0,24 \%$ citado por ROSTAGNO et al. (2005), mas muito próximo do valor de 0,32\% encontrado por CROMWELL et al. (1999) ao analisarem FS de diferentes regiões dos Estados Unidos.

Não houve diferenças $(\mathrm{P}>0,05)$ para $\mathrm{P}, \mathrm{K}$, $\mathrm{Mg}$, Cu e Zn, sendo os valores próximos aos citados por ROSTAGNO et al. (2005), exceto para o Mg, cuja concentração média encontrada neste estudo foi aproximadamente $50 \%$ superior à citada por aqueles autores $(0,41$ e $0,21 \%)$. Todavia, em outro estudo realizado para avaliar a concentração de Mg de vários tipos de FS, foram encontrados valores com amplitude de 0,26 a 0,41\% de Mg (KARR-LILIENTHAL et al., 2004).
Ocorreram diferenças $(\mathrm{P}<0,01)$ entre a concentração de Fe dos FS analisados. A quantidade de Fe detectada no presente estudo foi cerca de 50\% superior à encontrada em outros trabalhos (ROSTAGNO et al., 2005). Mesmo assim, é possível encontrar na literatura FS com conteúdo de Fe próximo ao detectado neste estudo (KARR-LILIENTHAL et al., 2004). O FS 10 foi o que apresentou conteúdo mais elevado $(\mathrm{P}<0,05)$ de Fe, enquanto o FS 4 foi o que teve a menor $(\mathrm{P}<0,01)$ quantidade de Fe analisada. O conteúdo de Mn variou $(\mathrm{P}<0,01)$ entre os FS analisados. Os FS 8 e 9 apresentaram maior $(\mathrm{P}<0,01)$ quantidade de $\mathrm{Mn}$ que os FS 3, 4, 6, 7 e 10, enquanto os FS 1, 2 e 5 mostraram valores intermediários e semelhantes $(\mathrm{P}>0,05)$ aos demais.

Houve diferenças $(\mathrm{P}<0,05)$ entre os valores de EMVn dos FS analisados. O FS 8 apresentou o maior conteúdo de EMVn, enquanto os FS 5 e 10 tiveram os menores $(\mathrm{P}<0,05)$ conteúdos. Os demais FS apresentaram valores intermediários e semelhantes $(\mathrm{P}>0,05)$ aos demais. Apesar das diferenças, o valor médio de EMVn foi próximo a outros valores citados na literatura (2,55 Mcal - ALBINO et al., 1992).

Todos os FS analisados apresentaram atividade ureática dentro da faixa recomendada (GRIESHOP et al., 2003), indicando que sofreram o processamento térmico adequado. Quanto à 
solubilidade da proteína, todos os farelos estão dentro dos limites de boa qualidade, apesar de ocorrerem diferenças $(\mathrm{P}<0,01)$ entre os FS estudados. Experimentos realizados com aves indicaram que FS com valores de solubilidade da proteína entre 73 e $85 \%$ podem ser considerados adequadamente processados (ARABE \& DALE, 1990).

A composição química dos farelos de soja das regiões oeste e sudoeste do Paraná apresenta pouca variação e os valores são próximos daqueles encontrados na literatura, exceto para a fibra em detergente neutro, fibra em detergente ácido, ferro e manganês.

\section{REFERÊNCIAS}

ALBINO, L.T.F. et al. Determinação dos valores de aminoácidos, energia metabolizável e proteína digestíva de alimentos para aves. Revista da Sociedade Brasileira de Zootecnia, v.21, n.6, p.1059-1068, 1992.

ARABE, M.; DALE, N.M. Evaluation of protein solubility as an indicator of overprocessing soybean meal. Poultry Science, v.69, n.1, p.76-83, 1990.

BUTOLLO, J.E. Qualidade de ingredientes na alimentação animal. Campinas: Colégio Brasileiro de Nutrição Animal, 2002. 430p.

COMPÊNDIO BRASILEIRO DE ALIMENTAÇÃO ANIMAL. São Paulo: SINDIRAÇÕES/ANFAL; Campinas: CBNA/SDR/ MA, 1998. 371p.

CROMWELL G.L. et al. Variability among sources and laboratories in nutrient analyses of corn and soybean meal. Journal of Animal Science, v.77, n.12, p.3262-3273, 1999.
GRIESHOP, C.M. et al. Chemical and nutritional characteristics of United States soybeans meals. Journal Agricultural Food Chemistry, v.51, n.26, p.7684-7691, 2003.

JANSSEN, W.M.M.A. European table of energy values for poultry feedstuffs. 3.ed. Beekbergen, The Netherlands: Spelderholt center for poutry research and information, 1989. 84p.

KARR-LILIENTHAL, L.K. et al. Chemical composition and protein quality comparisons of soybeans and soybean meals from five leading soybean-producing countries. Journal of Agricultural and Food Chemistry, v.52, n.20, p.6193-6199, 2004.

KARR-LILIENTHAL, L.K. et al. Amino acid, carbohydrate, and fat composition of soybean meals prepared at 55 commercial U.S. soybean processing plants. Journal of Agricultural and Food Chemistry, v.53, n.6, p.2146-2150, 2005.

OST, P.R. et al. Valores energéticos de sojas integrais e de farelos de soja, determinados com galos adultos e por equações de predição. Ciência e Agrotecnologia, v.29, n.2, p.467475, 2005.

RODRIGUES, P.B. et al. Aminoácidos digestíveis verdadeiros da soja e subprodutos. Revista Brasileira de Zootecnia, v.31, n.2 (sup.), p.970-987, 2002.

ROSTAGNO, H.S. et al. Tabelas brasileiras para aves e suínos: composição de alimentos e exigências nutricionais. 2.ed. Viçosa: UFV, Departamento de Zootecnia, 2005. 186p.

VAN KEMPEN, T.A.T.G. et al. Regional and processor variation in the ileal digestible amino acid content of soybean meals measured in growing swine. Journal of Animal Science, v.80, n.2, p.429-439, 2002. 